\title{
Modeling and Solving Production Planning Problem under Uncertainty: A Case Study
}

\author{
Samir A. Abass ${ }^{1}$, Marwa She hata Els aye d ${ }^{2, *}$ \\ ${ }^{2}$ Atomic Energy Authority,Cairo, Eygypt \\ ${ }^{2}$ Institute of culture and science, $6^{\text {th }}$ October city, Cairo, Egypt
}

\begin{abstract}
Data in many real life engineering and economical proble ms suffer fro $m$ ine xactness. In the real world there are many forms of uncertainty that affect production processes. Uncertainty always exists in practical engineering problems. in order to deal with the uncertain optimization problems, fuzzy and stochastic approaches are commonly used to describe the imprec ise characteristics. Herein we assume some intervals in which the data can simultaneously and independently perturb. In this study production planning related data of Al- Araby firm for electric sets in Egypt was collected. A production planning model based on linear programming (LP) was formulated. This formulation based on the outcomes of collected data. The data includes the amount of required and available resources, the demand, the cost of production, the cost of unmet demand, the cost of inventory holding and the revenue. in this work, the objective is to maximize the revenues net of the production, inventory and lost sales costs. The general LP model was solved by using software named W in QSB.
\end{abstract}

Keywords Production Planning, Stability, Linear Programming, Interval Numbers, Para metric Study

\section{Introduction}

The objective of the production planning problem is the maximization of the revenue. For solving it, the demand and resource levels are assumed to be fixed and given. But a production planning problem exists because there are limited production resources that cannot be stored from period to period. Also the planning problem starts with a specification of customer demand that is to be met by the production plan. In most contexts, future demand is partially known. So one relies on a forecast for the future demand but the forecast is inaccurate. This leads to that demand that cannot be met in a period is lost, thus reducing revenue. So a production planning problem to maximize revenues net of the production, inventory and lost sales costs is suggested by Stephen C. Graves[1]. For solving it, the coefficients of the objective function, the inequalities and the equalities constraints are assumed to be known numbers.

In real world, the data are imp recise that is the data can be represented as uncertainty. In the real world there are many forms of uncertainty that affect production processes. Uncertainty always exits in practical engineering problems. In order to deal with the uncertain optimization problems, fuzzy and stochastic approaches are commonly used to describe the imprecise characteristics. In stochastic

* Corresponding author:

marwa_shehata2003@yahoo.com (Marwa Shehata Elsayed)

Published online at http://journal.sapub.org/ajor

Copyright (C) 2012 Scientific \& Academic Publishing. All Rights Reserved programming[20] the uncertain coefficients are regarded as random variables and their probability distributions are assumed to be known. In fuzzy programming[21] the constraints and objective function are viewed as fuzzy sets and their membership functions also need to be known. In these two kinds of approaches, the membership functions and probability distributions play important roles. It is sometimes difficult to specify an appropriate membership function or accurate probability distribution in an uncertain environment[22]. The interval analysis method was developed to model the uncertainty in uncertain optimization problems, in which the bounds of the uncertain coefficients are only required, not necessarily knowing the probability distributions or membership functions. So for the first time, we will deal the production planning problem with interval data as uncertainty in both of the objective function and constraints.

\section{Review Literature}

Production planning is a complicated task which requires cooperation among multiple functional units in an organization. For solving the problem of production planning, powerful optimization models have been constructed by means of the formulation of mathematical programming. We refer to[1,7] for an overview of optimization techniques in this field.

Galbraith[3] defines uncertainty as the difference between the amount of information required to perform a task and the amount of information already possessed. we refer to[13] for 
applying a fuzzy linear programming method for solving model related to aggregate production planning problem with multiple objectives. also we refer to[19] for applying a stochastic linear programming method for solving model related to supply chain planning with bi-level linear multiple objective programming. As the recent contribution for the problem of concern can be viewed as follows:

R. Svend[23] discusses how the linear programming model can be used as the basis for a company's operational planning, in practice. F. G. Juan Carlos et al.[24] developed a new model for production planning using fuzzy sets in order to use classical mathematical programming techniques to reach an optimal solution over a multiple criteria context.

Production planning problem that involve the lost of future demand have been investigated by Stephen C. Graves[1]. This problem deals with precise coefficients in both of objective function, the inequalities and the equalities constraints. While the data in the real world are imprecise then the input data can be represented as uncertainty.

In our work, we develop a new planning problem to minimize the lost demands and thus maximize revenues. For the first time, we construct the production planning problem with interval numbers as uncertainty in both of the objective function and constraints. After that we will treat the uncertain of objective function and constraints. In section 5, parametric study for the treatment problem is introduced. Finally, for illustration, a production planning example is given, where the integer programming optimal solution is determined using the WinQSB software package.

\section{Solution Algorithm}

In this sub section, we describe a solution algorith $\mathrm{m}$ for solving problem (1)-(14).

Algorith m steps:

Step 1: Construct the production planning problem with interval numbers in both of the objective function and constraints as in (1)-(14).

Step 2: Read the interval values of $\left[b_{k t}^{L}, b_{k t}^{R}\right],\left[d_{i t}^{L}, d_{i t}^{R}\right]$ and the values of $r_{i t}, c p_{i t}, c q_{i t}, c u_{i t}, a_{i k}, \lambda_{k t}$ where $i=1,2,3, t=1,2, k=$ $1,2,3$.

Step 3: Convert the problem (1)-(14) to the determin istic form (45)-(64).

Step 4: solve the problem by WinQSB software package.

Step 5: Stop.

\section{Methodology Adopted}

In this study, production related data of Al- Araby firm for electric sets in Egypt was collected. Data was collected, classified and analyzed statistically. Linear programming model was formulated based on the outcomes of the analyzed data. The data were collected through the use of questionnaires and oral interview among employees in the firm. The data that were collected include the following:

The firm is planning for production of three items: refrigerators, ovens and washing machines. The manufacturer of each item requires three resources. These resources are number of workers, over time and varying inventory. There are two time periods for production. The length of each time period is six months. The amount of the three resources required of production of the three items is illustrated in table (1). The amounts of availab le resource and demand for each item are represented by interval numbers as illustrated in tables (2) and (3) respectively. The cost of production of the three items in a given two time periods is illustrated in table (4). The unit cost of unmet demand of the three items in a given two time periods is illustrated in table (5). The unit inventory holding costs of the three items in a given two time periods is illustrated in table (6). The unit revenue for each item in each time period is illustrated in table (7).

Table 1. Required resources of production

\begin{tabular}{|c|c|c|c|}
\hline Total required & \multicolumn{3}{|c|}{ Production requirements } \\
resou rces $a_{i k}$ & \multicolumn{3}{|c|}{} \\
\hline & Refrigerat ors & Ovens & $\begin{array}{c}\text { washing } \\
\text { machines }\end{array}$ \\
\hline Number of workers & 8 & 6 & 5 \\
\hline Overtime & 4 & 3 & 5 \\
\hline Varying inventory & 30 & 50 & 60 \\
\hline
\end{tabular}

Table 2. Amounts of available resources

\begin{tabular}{|c|c|c|}
\hline $\begin{array}{c}\text { Total available } \\
\text { resou rces }\end{array}$ & \multicolumn{2}{|c|}{ Production re qui rements } \\
{$\left[b_{k t}^{L}, b_{k t}^{R}\right]$} & \multicolumn{2}{|c|}{} \\
\hline & Time period 1 & 2Time period \\
\hline Number of workers & $, 130) \mathbf{6 0}$ & $(70,100)$ \\
\hline Overtime & $(500,700)$ & $(500,700)$ \\
\hline Varying inventory & $(60,80)$ & $(80,90)$ \\
\hline
\end{tabular}

Table 3. Amounts of demand resources

\begin{tabular}{|c|c|c|}
\hline $\begin{array}{c}\text { Production } \\
\text { re qui rements }\end{array}$ & \multicolumn{2}{|c|}{ The demand $\left[d_{i t}^{L}, d_{i t}^{R}\right]$} \\
\hline & Time period 1 & 2Time period \\
\hline Refrigerators & $(5000,7000)$ & $(7000,9000)$ \\
\hline Ovens & $(5000,7000)$ & $(7000,9000)$ \\
\hline washing machines & $(5000,7000)$ & $(7000,9000)$ \\
\hline
\end{tabular}

Table 4. Production cost of three items

\begin{tabular}{|c|c|c|}
\hline $\begin{array}{c}\text { Production } \\
\text { requirements }\end{array}$ & \multicolumn{2}{|c|}{ Cost of production $c p_{i t}$} \\
\hline & Time period 1 & 2Time period \\
\hline Refrigerators & 1500 & 1550 \\
\hline Ovens & 1000 & 1050 \\
\hline washing machines & 1500 & 1550 \\
\hline
\end{tabular}


Table 5. Unit cost of unmet demand

\begin{tabular}{|c|c|c|}
\hline $\begin{array}{c}\text { Production } \\
\text { requirements }\end{array}$ & \multicolumn{2}{|c|}{ Cost of unmet demand $c u_{i t}$} \\
\hline & Time period 1 & 2Time period \\
\hline Refrigerators & 100 & 120 \\
\hline Ovens & 70 & 70 \\
\hline washing machines & 90 & 100 \\
\hline
\end{tabular}

Table 6. Unit inventory holding costs

\begin{tabular}{|c|c|c|}
\hline $\begin{array}{c}\text { Production } \\
\text { requi rements }\end{array}$ & \multicolumn{2}{|c|}{ Cost of in ventory hol ding $c q_{i t}$} \\
\hline & Time period 1 & 2Time period \\
\hline Refrigerators & 30 & 30 \\
\hline Ovens & 20 & 15 \\
\hline washing machines & 25 & 20 \\
\hline
\end{tabular}

Table 7. unit revenue of each item in each period

\begin{tabular}{|c|c|c|}
\hline $\begin{array}{c}\text { Production } \\
\text { requi rements }\end{array}$ & \multicolumn{2}{|c|}{ The re venue $r_{i t}$} \\
\hline & Time period 1 & 2Time period \\
\hline Refrigerators & $\mathbf{3 0 0 0}$ & $\mathbf{3 5 0 0}$ \\
\hline Ovens & $\mathbf{2 0 0 0}$ & $\mathbf{2 5 0 0}$ \\
\hline washing machines & $\mathbf{3 0 0 0}$ & $\mathbf{3 5 0 0}$ \\
\hline
\end{tabular}

The decision variables are as follows:

$p_{11}=$ the amount of production of refrigerators during time period 1 .

$p_{12}=$ the amount of production of refrigerators during time period 2 .

$p_{21}=$ the amount of production of ovens during time period 1 .

$p_{22}=$ the amount of production of ovens during time period 2 .

$p_{31}=$ the amount of production of washing machines during time period 1 .

$p_{32}=$ the amount of production of washing machines during time period 2 .

$q_{11}=$ the amount of inventory of refrigerators at end of time period 1 .

$q_{12}=$ the amount of inventory of refrigerators at end of time period 2 .

$q_{21}=$ the amount of inventory of ovens at end of time period 1 .

$q_{22}=$ the amount of inventory of ovens at end of time period 2.

$q_{31}=$ the amount of inventory of washing machines at end of time period 1 .

$q_{32}=$ the a mount of inventory of washing machines at end of time period 2 .

$u_{11}=$ the amount of unmet demand of refrigerators during time period 1 .

$u_{12}=$ the amount of unmet demand of refrigerators during time period 2 .

$u_{21}=$ the amount of unmet demand of ovens during time period 1 .

$u_{22}=$ the amount of unmet demand of ovens during time period 2 .

$u_{31}=$ the amount of unmet demand of washing machines during time period 1 .

$u_{32}=$ the amount of unmet demand of washing machines during time period 2.

With these variables, it is possible to formulate the production planning problem that maximizes revenues net of the production inventory and lost sales cost with interval numbers as follows:

Maximize $Z$

$$
\begin{gathered}
=3000\left(\left[d_{11}^{L}, d_{11}^{R}\right]-u_{11}\right)+3500\left(\left[d_{12}^{L}, d_{12}^{R}\right]-u_{12}\right) \\
+2000\left(\left[d_{21}^{L}, d_{21}^{R}\right]-u_{21}\right)+2500\left(\left[d_{22}^{L}, d_{22}^{R}\right]-u_{22}\right) \\
+3000\left(\left[d_{31}^{L}, d_{31}^{R}\right]-u_{31}\right)+3500\left(\left[d_{32}^{L}, d_{32}^{R}\right]-u_{32}\right) \\
-1500 p_{11}-1550 p_{12}-1000 p_{21}-1050 p_{22} \\
-1500 p_{31}-1550 p_{32}-30 q_{11}-30 q_{12}-20 q_{21} \\
-15 q_{22}-25 q_{31}-20 q_{32}-100 u_{11}-120 u_{12} \\
-70 u_{21}-70 u_{22}-90 u_{31}-100 u_{32}
\end{gathered}
$$

subject to

$$
\begin{gathered}
8 p_{11}+6 p_{21}+5 p_{31} \leq\left[b_{11}^{L}, b_{11}^{R}\right] \\
8 p_{12}+6 p_{22}+5 p_{32} \leq\left[b_{12}^{L}, b_{12}^{R}\right] \\
4 p_{11}+3 p_{21}+5 p_{31} \leq\left[b_{21}^{L}, b_{21}^{R}\right] \\
4 p_{12}+3 p_{22}+5 p_{32} \leq\left[b_{22}^{L}, b_{22}^{R}\right] \\
30 p_{11}+50 p_{21}+60 p_{31} \leq\left[b_{31}^{L}, b_{31}^{R}\right] \\
30 p_{12}+50 p_{22}+60 p_{32} \leq\left[b_{32}^{L}, b_{32}^{R}\right] \\
p_{11}-q_{11}+u_{11}=\left[d_{11}^{L}, d_{11}^{R}\right] \\
q_{11}+p_{12}-q_{12}+u_{12}=\left[d_{12}^{L}, d_{12}^{R}\right] \\
p_{21}-q_{21}+u_{21}=\left[d_{21}^{L}, d_{21}^{R}\right] \\
q_{21}+p_{22}-q_{22}+u_{22}=\left[d_{22}^{L}, d_{22}^{R}\right] \\
p_{31}-q_{31}+u_{31}=\left[d_{31}^{L}, d_{31}^{R}\right] \\
q_{31}+p_{32}-q_{32}+u_{32}=\left[d_{32}^{L}, d_{32}^{R}\right] \\
p_{11}, p_{12}, p_{21}, p_{22}, p_{31}, p_{32}, q_{11}, q_{12}, q_{21} \\
q_{22}, q_{31}, q_{32}, u_{11} u_{12} u_{21} u_{22} u_{31} u_{32} \geq 0
\end{gathered}
$$




\section{The Optimization Approach}

Based on the proposed approach of Jiang[8] for treating interval number, we will treat the uncertainty of model (1)-(14) as follows:

\section{First: Treatment of the uncertain objective function}

Let

$$
\begin{gathered}
f(p, q, u, d)=3000\left(\left[d_{11}^{L}, d_{11}^{R}\right]-u_{11}\right) \\
+3500\left(\left[d_{12}^{L}, d_{12}^{R}\right]-u_{12}\right)+2000\left(\left[d_{21}^{L}, d_{21}^{R}\right]-u_{21}\right) \\
+2500\left(\left[d_{22}^{L}, d_{22}^{R}\right]-u_{22}\right)+3000\left(\left[d_{31}^{L}, d_{31}^{R}\right]-u_{31}\right) \\
+3500\left(\left[d_{32}^{L}, d_{32}^{R}\right]-u_{32}\right)-1500 p_{11}-1550 p_{12} \\
-1000 p_{21}-1050 p_{22}-1500 p_{31}-1550 p_{32}-30 q_{11} \\
-30 q_{12}-20 q_{21}-15 q_{22}-25 q_{31}-20 q_{32}-100 u_{11} \\
-120 u_{12}-70 u_{21}-70 u_{22}-90 u_{31}-100 u_{32}
\end{gathered}
$$

in interval mathematics, The uncertain objective function (1) can be trans formed into two objective optimization problems as follows:

$$
\begin{aligned}
& m(f(p, q, u, d))=\frac{1}{2}\left(f^{R}(p, q, u, d)+f^{L}(p, q, u, d)\right), \\
& w(f(p, q, u, d))=\frac{1}{2}\left(f^{R}(p, q, u, d)-f^{L}(p, q, u, d)\right) .
\end{aligned}
$$

where $m$ is called the midpoint value, $w$ is called the radius of interval number and the two functions $f^{L}$ and $f^{R}$ are given as follows:

$$
\begin{aligned}
& f^{L}(p, q, u, d)=\min _{d \in D} f(p, q, u, d) \\
& f^{R}(p, q, u, d)=\max _{d \in D} f(p, q, u, d) \\
& d \in D=\left\{d \mid d^{L}<d<d^{R}\right\} \text {. } \\
& \text { Then } \\
& m=1500\left(d_{11}^{R}-u_{11}\right)+1750\left(d_{12}^{R}-u_{12}\right)+1000\left(d_{21}^{R}-u_{21}\right) \\
& +1250\left(d_{22}^{R}-u_{22}\right)+1500\left(d_{31}^{R}-u_{31}\right)+1750\left(d_{32}^{R}-u_{32}\right) \\
& +1500\left(d_{11}^{L}-u_{11}\right)+1750\left(d_{12}^{L}-u_{12}\right)+1000\left(d_{21}^{L}-u_{21}\right) \\
& +1250\left(d_{22}^{L}-u_{22}\right)+1500\left(d_{31}^{L}-u_{31}\right)+1750\left(d_{32}^{L}-u_{32}\right) \\
& -1500 p_{11}-1550 p_{12}-1000 p_{21}-1050 p_{22} \\
& -1500 p_{31}-1550 p_{32}-30 q_{11}-30 q_{12}-20 q_{21} \\
& -15 q_{22}-25 q_{31}-20 q_{32}-100 u_{11}-120 u_{12} \\
& -70 u_{21}-70 u_{22}-90 u_{31}-100 u_{32} \\
& +1250\left(d_{22}^{R}-u_{22}\right)+1500\left(d_{31}^{R}-u_{31}\right)+1750\left(d_{32}^{R}-u_{32}\right) \\
& -1500\left(d_{11}^{L}-u_{11}\right)-1750\left(d_{12}^{L}-u_{12}\right)-1000\left(d_{21}^{L}-u_{21}\right) \\
& -1250\left(d_{22}^{L}-u_{22}\right)-1500\left(d_{31}^{L}-u_{31}\right)-1750\left(d_{32}^{L}-u_{32}\right)(19)
\end{aligned}
$$

\section{Second: Treatment of the uncertain constraints}

The possibility degree of interval number represents certain degree that one interval number is larger or s maller than another. The set of inequality constraints (2)-(7) can be written as

$$
\begin{gathered}
-8 p_{11}-6 p_{21}-5 p_{31} \geq-\left[b_{11}^{L}, b_{11}^{R}\right] \\
-8 p_{12}-6 p_{22}-5 p_{32} \geq-\left[b_{12}^{L}, b_{12}^{R}\right] \\
-4 p_{11}-3 p_{21}-5 p_{31} \geq-\left[b_{21}^{L}, b_{21}^{R}\right] \\
-4 p_{12}-3 p_{22}-5 p_{32} \geq-\left[b_{22}^{L}, b_{22}^{R}\right] \\
-30 p_{11}-50 p_{21}-60 p_{31} \geq-\left[b_{31}^{L}, b_{31}^{R}\right] \\
-30 p_{12}-50 p_{22}-60 p_{32} \geq-\left[b_{32}^{L}, b_{32}^{R}\right]
\end{gathered}
$$

As in interval linear programming[18], the possibility degree of the constraints (20) can be written as follows

$$
\begin{aligned}
& P_{-8 p_{11}-6 p_{21}-5 p_{31} \geq-\left[b_{11}^{L}, b_{11}^{R}\right]}= \\
& \begin{cases}0, & -8 p_{11}-6 p_{21}-5 p_{31}<-b_{11}^{L}, \\
\frac{-8 p_{11}-6 p_{21}-5 p_{31}+b_{11}^{L}}{-b_{11}^{R}+b_{11}^{L}}, & -b_{11}^{L} \leq-8 p_{11}-6 p_{21}-5 p_{31}<-b_{11}^{R}, \\
1, & -8 p_{11}-6 p_{21}-5 p_{31} \geq-b_{11}^{R}\end{cases} \\
& P_{-8 p_{11}-6 p_{21}-5 p_{31} \geq-\left[b_{11}^{L}, b_{11}^{R}\right]} \geq \lambda_{11} \text { is the possibility degree of } \\
& b_{11}^{L}-8 p_{11}-6 p_{21}-5 p_{31} \geq-\lambda_{11}\left(b_{11}^{L}-b_{11}^{R}\right) \\
& b_{12}^{L}-8 p_{12}-6 p_{22}-5 p_{32} \geq-\lambda_{12}\left(b_{12}^{L}-b_{12}^{R}\right) \\
& b_{21}^{L}-4 p_{11}-3 p_{21}-5 p_{31} \geq-\lambda_{21}\left(b_{21}^{L}-b_{21}^{R}\right) \\
& b_{22}^{L}-4 p_{12}-3 p_{22}-5 p_{32} \geq-\lambda_{22}\left(b_{22}^{L}-b_{22}^{R}\right) \\
& b_{31}^{L}-30 p_{11}-50 p_{21}-60 p_{31} \geq-\lambda_{31}\left(b_{31}^{L}-b_{31}^{R}\right) \\
& b_{32}^{L}-30 p_{12}-50 p_{22}-60 p_{32} \geq-\lambda_{32}\left(b_{32}^{L}-b_{32}^{R}\right)
\end{aligned}
$$

The equality constraints (8)-(13) can be treated as follows $d_{11}^{L} \leq p_{11}-q_{11}+u_{11} \leq d_{11}^{R}$ that can be written as

$$
\begin{gathered}
p_{11}-q_{11}+u_{11} \leq d_{11}^{R} \\
\text { and } p_{11}-q_{11}+u_{11} \geq d_{11}^{L}
\end{gathered}
$$

the other equality constraints are treated in the same way. Then the constraints (9)-(13) can be written as

$$
\begin{gathered}
q_{11}+p_{12}-q_{12}+u_{12} \leq d_{12}^{R} \\
q_{11}+p_{12}-q_{12}+u_{12} \geq d_{12}^{L} \\
p_{21}-q_{21}+u_{21} \leq d_{21}^{R} \\
p_{21}-q_{21}+u_{21} \geq d_{21}^{L} \\
q_{21}+p_{22}-q_{22}+u_{22} \leq d_{22}^{R}
\end{gathered}
$$




$$
\begin{gathered}
q_{21}+p_{22}-q_{22}+u_{22} \geq d_{22}^{L} \\
p_{31}-q_{31}+u_{31} \leq d_{31}^{R} \\
p_{31}-q_{31}+u_{31} \geq d_{31}^{L} \\
q_{31}+p_{32}-q_{32}+u_{32} \leq d_{32}^{R} \\
q_{31}+p_{32}-q_{32}+u_{32} \geq d_{32}^{L}
\end{gathered}
$$

\section{The Deterministic form of Problem (1)-(14)}

The linear co mbination method[2,5,6] is adopted with the multi objective optimization. In multi objective optimization, applying the linear combination method to integrate the objective function is relatively easy provided that the preferences of the objective functions are available. Then two objective function (18), (19) can be written in the form of only one objective function.

Maximize $\mathrm{Z}$

$$
\begin{gathered}
=60000000-750 p_{11}-775 p_{12}-500 p_{21}-525 p_{22} \\
-750 p_{31}-775 p_{32}-15 q_{11}-15 q_{12}-10 q_{21}-7.5 q_{22} \\
-12.5 q_{31}-10 q_{32}-3000 u_{11}-3500 u_{12}-2000 u_{21} \\
-2500 u_{22}-3000 u_{31}-3500 u_{32}
\end{gathered}
$$

subject to

$$
\begin{aligned}
& 8 p_{11}+6 p_{21}+5 p_{31} \leq 50 \\
& 8 p_{12}+6 p_{22}+5 p_{32} \leq 60 \\
& 4 p_{11}+3 p_{21}+5 p_{31} \leq 400 \\
& 4 p_{12}+3 p_{22}+5 p_{32} \leq 400 \\
& 30 p_{11}+50 p_{21}+60 p_{31} \leq 50 \\
& 30 p_{12}+50 p_{22}+60 p_{32} \leq 80
\end{aligned}
$$

$$
\begin{gathered}
p_{11}-q_{11}+u_{11} \leq 7000 \\
p_{11}-q_{11}+u_{11} \geq 5000 \\
q_{11}+p_{12}-q_{12}+u_{12} \leq 9000 \\
q_{11}+p_{12}-q_{12}+u_{12} \geq 7000 \\
p_{21}-q_{21}+u_{21} \leq 7000 \\
p_{21}-q_{21}+u_{21} \geq 5000 \\
q_{21}+p_{22}-q_{22}+u_{22} \leq 9000 \\
q_{21}+p_{22}-q_{22}+u_{22} \geq 7000 \\
p_{31}-q_{31}+u_{31} \leq 7000 \\
p_{31}-q_{31}+u_{31} \geq 5000 \\
q_{31}+p_{32}-q_{32}+u_{32} \leq 9000 \\
q_{31}+p_{32}-q_{32}+u_{32} \geq 7000 \\
p_{11}, p_{12}, p_{21}, p_{22}, p_{31}, p_{32}, q_{11}, q_{12}, q_{21},
\end{gathered}
$$$$
q_{22}, q_{31}, q_{32}, u_{11} u_{12} u_{21} u_{22} u_{31} u_{32} \geq 0
$$

By using WinQSB package for solving this problem, we get the optimal solution as follows:

Net revenue $Z=\$ 2,951,510$

$$
p_{12}=2250 \quad, \quad p_{21}=5000 \quad, \quad p_{22}=7000 \text {, }
$$$$
p_{31}=4000, q_{11}=4750, u_{11}=9000, u_{31}=1000 \text {, }
$$

$u_{32}=6700$ and all other variables equal zero.

Table (8) shows the comparis on between the results of our approach which is based on uncertainty case and one's of Stephen C. Graves approach[1] which is based on the deterministic case.

It is clear that the results obtained from our approach are better than the results obtained by Stephen C. Graves especially for the objective function value.

Table 8. comparison results between our approach and one's Stephen C. Graves[1]

\begin{tabular}{|c|c|}
\hline Results obtained from our approach & Results obtained from the model of Stephen $\mathrm{C}$. Graves \\
\hline Objective function value $=\$ 2,951,510$ & Objective function value $=\$ 2,386,693$ \\
\hline Variables: & Variables: \\
$p_{12}=2250, p_{21}=5000$, & $p_{11}=2273, p_{21}=8636, p_{22}=7364$, \\
$p_{22}=7000, p_{31}=4000$, & $p_{32}=3163, q_{11}=9000, q_{21}=1636$ \\
$q_{11}=4750, u_{11}=9000$, & $, q_{31}=5837, u_{11}=9000, u_{31}=1000$, \\
$u_{31}=1000, u_{32}=6700$ & and all other variables equal zero \\
and all other variables equal zero & \\
\hline
\end{tabular}




\section{Conclusions}

In this paper,

However, as a point for future research, a comparison study is needed between the interval and fuzzy programming to tackle the production planning problem, where each of fuzzy programming and interval programming are two forms of uncertainty. This point for future research is to determine which of interval and fuzzy programming is more suitable for problem of concern.

\section{REFERENCES}

[1] Stephen C. Graves, "Manufacturing planning and control". Massachusetts institute of technology, November 1999.

[2] S. Chanas and D. Kuchta "Multiobjective programming in optimization of interval objective function a generalized approach". European Journal of Operational Research 94, 594-598, 1996

[3] J. Galbraith, Designing Complex Organizations. Addison-Wesley, Reading, MA. (1973).

[4] A.C. Hax and H.C. Meal "Hierarchical integration of production planning and scheduling". In Studies in Management Science, Vol.1: Logistics,edited by M.A. Geisler, New York, Elsevier, 53-69, 1975.

[5] Y.D. Hu "Applied multiobjective optimization". Shanghai Science and Technology Press, Shanghai, China, 1990.

[6] H. Ishibuchi and H. Tanaka "Multiobjective programming in optimization of the interval objective function". European Journal of Operational Research 48, 219-225, 1990.

[7] A. Jamalnia and M. Ali Soukhakian "A hybrid fuzzy goal programming approach with different goal priorities to aggregate production planning". Computers \& Industrial Engineer ing 56, 1474-1486, 2009.

[8] C. Jiang “A nonlinear interval number programming method for uncertain optimization problems". European Journal of Operational Research 188, 1-13, 2008.

[9] L.H. Ma "Research on method and application of robust optimization for uncertain system" Ph.D.dissertation, Zhejiang University, China, 2002.

[10] J. Mula, R. Poler, J.P. Garcia-Sabater, and F.C. Lario "Models for production planning under uncertainty" International Journal of Production Economics 103, 271-285, 2006
[11] M. Osman "Qualitative analysis of basic notions in parametric programmingII (parameters in the objective function)" ApplMath 22, 1977.

[12] M. Osman and A.H. El-Banna, "Stability of multiobjective nonlinear programming problems with fuzzy parameters". Math. Comput. Simulation 35, 321-326, 1993.

[13] Wang R., Fang H. 2001 “Aggregate Production Planning Problem with Multiple Objectives in A Fuzzy Environment". European Journal of Operational Research Vol. 133, PP. 521-536.

[14] Cormier G., Rezg N. "A simulation Model for Joint Production Planning Policies for Molds and End Items" In International Conference on Industrial Engineering and Systems Management, Beijing, China, 2007.

[15] Gilles Cormier and N. Rezg "An integrated Production planning model for molds and end items" International Journal of Production Economics, Vol. 121, No. 1, PP. 68-71, 2009.

[16] E. Vicens, M.E. Alemany, C. Andres and J.J. Guarch (2001) "Adesign and application methodology for hierarchical production planning decision support systems in an enterprise integration context" Int. J. Production Economics 74(5-20)

[17] Mula J., Poler R., Peidro D., Verdegay J., 2009. “ Fuzzy Optimization for Supply Chain Planning under Supply, Demand and Process Uncertainty". Fuzzy Sets and Systems, Vol. 160, No. 18, PP. 2640-2657.

[18] Q. Zhang, Z.P. Fan and D.H. Pan "A ranking approach for interval numbers in uncertain multiple attribute decision making problems" Systems Engineering - Theory \& Practice 5, 129-133, 1999.

[19] Roghanian E., Sadjadi S.J. and Aryanezhad M.B. (2007) " A probabilistic bi-level linear multi-objective programming problem to supply chain planning" Applied Mathematics and Computation, 188(1), 786-800.

[20] Cho, Gyeong-Mi, 2005. "Log-barrier method for two-stage quadratic stochastic programming". Applied Mathematics and Computation 164(1), 45-69.

[21] Liu, B.D., Iwamura, K., 2001. "Fuzzy programming with fuzzy decisions and fuzzy simulation-based genetic algorithm". Fuzzy Sets and Systems 122(2), 253-262.

[22] Sengupta, A., Pal, T.K., Chakraborty, D., 2001. "Interpretation of inequality constraints involving interval coefficients and a solution to interval linear programming". Fuzzy Sets and Systems 119, 129-138.

[23] R. Svend, 2011. "Production economics, the basics theory of production optimization". Springer Verlag, 225-260.

[24] F. G. Juan Carlos , 2012. " Multi-period mixed production planning with uncertain demands: fuzzy and interval fuzzy sets approach. 